\title{
PERSPECTIVAS DOS ACADÊMICOS INICIANTES E CONCLUINTES DO CURSO DE CIÊNCIAS CONTÁBEIS EM RELAÇÃO À PROFISSÃO CONTÁBIL UNEMAT - CAMPUS TANGARÁ DẢ SERRA-MT
}

\author{
Lucivone Pereira Gomes ${ }^{1}$ \\ Margarida Alves Rocha ${ }^{2}$ \\ Carlos Rezende de Pádua Júnior ${ }^{3}$ \\ Fabiana Pereira Leite Lancelotti de Oliveira ${ }^{4}$
}

\begin{abstract}
RESUMO
É importante que o acadêmico após concluir a graduação busque estudo continuado, fazendo especializações, pois, o mercado exige cada vez mais profissionais que tenham interesse na contínua busca de informações mantendo-se atualizado, acompanhando as constantes mudanças que vem ocorrendo em todo cenário mundial. A pesquisa teve como objetivo identificar e demonstrar os motivos, expectativas e influências que contribuíram para os acadêmicos na escolha do curso de ciências contábeis. Utilizando como método de pesquisa levantamento por meio de questionário objetivo contendo treze perguntas. A amostra para os iniciantes e população para os concluintes, realizado somente em uma etapa. Os resultados dessa pesquisa mostram que os objetivos e as hipóteses foram alcançados tornando-a relevante. Os alunos responderam que possuem boa perspectiva com relação ao curso que buscaram como profissão futura, e que o mesmo proporciona variedades de atuação no mercado com boas expectativas. Percebeu-se que os entrevistados gostam do curso e também buscam com o curso grande atuação na área pública. Os ingressantes buscam carreiras como auditores ou contadores. Os concluintes, não sabem qual carreira pretendem seguir. Há consenso entre concluintes e ingressantes que o curso é bom preparo para a carreira em órgãos públicos.
\end{abstract}

Palavras Chave: Ensino superior; Contabilidade; Perfil profissional.

\section{INTRODUÇÃO}

A contabilidade na atualidade se tornou uma ferramenta de fundamental importância, pois, contribui para o desenvolvimento e a continuidade das organizações, gerando informações que influenciam nas tomadas de decisões. Neste contexto a capacitação do profissional contábil vem prospectar melhores resultados que atendam as necessidades dessas organizações.

Os acadêmicos quando ingressam na universidade podem, de certa maneira, ter algumas noções distorcidas do curso, por não ter um conhecimento aprofundado. Portanto, essas idéias podem se modificar no decorrer do curso.

O profissional contábil desenvolve papel significativo dentro das entidades, fornecendo informações que são necessárias para avaliar e analisar as mais diversas situações que as empresas encontram durante as atividades diárias, informações essas que contribui para melhorar os vários níveis de atividades das entidades entre outros. Com esse estudo pretendeu-se identificar a visão dos acadêmicos iniciantes (2010/2) e concluintes (2007/1) do curso de ciências contábeis e o seu campo de atuação profissional.

\footnotetext{
${ }^{1}$ Acadêmica de Ciências Contábeis, UNEMAT, e-mail: lukkagomes@ hotmail.com

${ }^{2}$ Professora do Departamento de Ciências Contábeis, UNEMAT, e-mail:margaridarocha@unemat.br

${ }^{3}$ Professor do Departamento de Ciências Contábeis, UNEMAT, e-mail: carlos.junior@unemat.br

${ }^{4}$ Professora do Departamento de Ciências Contábeis, UNEMAT, fabiana.lancelotti@unemat.br 
Perspectivas dos acadêmicos iniciantes e concluintes do curso de Ciências Contábeis em relação à profissão contábil UNEMAT - campus Tangará da Serra-MT

Lucivone Pereira Gomes, Margarida Alves Rocha, Carlos Rezende de Pádua Júnior, Fabiana Pereira Leite Lancelotti de Oliveira

Diante disto, foi proposto o problema: Quais são as expectativas dos acadêmicos do curso de Ciências Contábeis iniciantes 2010/2 e concluintes 2007/1 em relação à profissão contábil?

As hipóteses elaboradas foram: H1-A escolha do curso de ciências contábeis pelos acadêmicos iniciantes e concluintes (2010/2 - 2007/1) reflete o desejo de serem profissionais liberais. H2 - Os acadêmicos têm como expectativa dessa profissão ingressar na área pública, (concursos públicos).

O objetivo geral foi verificar qual motivação e influências que contribuíram para os acadêmicos iniciantes 2010/2 e concluintes 2007/1 do Curso de Ciências Contábeis, UNEMAT- campus Tangará da Serra - MT em relação à profissão Contábil. Os objetivos específicos foram os seguintes: Identificar o que motivou os acadêmicos iniciantes (2010/2 2007/1) na escolha do curso de ciências contábeis; Verificar as expectativas dos acadêmicos (2010/2-2007/1) em relação ao curso de ciências contábeis quanto à profissão contábil; Demonstrar as opiniões e as expectativas em relação à profissão contábil tanto dos acadêmicos iniciantes (2010/2) quanto dos concluintes (2007/1).

\title{
2 REFERENCIAL TEÓRICO
}

Esta seção tem o objetivo de estabelecer os conceitos fundamentais para a compreensão da pesquisa. São apresentados os conceitos, objetivos e evolução da contabilidade. Em seguida são abordados os temas, perspectiva da profissão contábil no Brasil, e a profissão do futuro.

A pesquisa do presente trabalho científico é desenvolvida por meio do embasamento teórico de idéias de autores renomados na área da profissão contábil.

De acordo Marion, (2004, p.26), "Contabilidade é o instrumento que fornece o máximo de informações úteis para a tomada de decisões dentro e fora de empresa”.

A contabilidade, portanto, é uma ciência social que tem por objeto o patrimônio das entidades econômico-administrativas. Seu objetivo principal é controlar o patrimônio das entidades em decorrência de suas variações. Para compreender o conceito de contabilidade, é preciso saber o conceito do que vem a ser patrimônio e o que significa entidade.

De acordo com Ribeiro (2009, p.2):

\begin{abstract}
A contabilidade, portanto, é uma ciência social que tem por objeto o patrimônio das entidades econômicas-administrativas. Seu objetivo principal é controlar o patrimônio das entidades em decorrência de suas variações. Para compreender o conceito de contabilidade, é preciso saber o que é patrimônio e o que é entidade.
\end{abstract}

A contabilidade tem como característica conforme citado acima pelos autores mostrar as informações existentes em relação às movimentações e os registros contábeis das entidades. É vista como ciência social, pois é direcionada para controlar o patrimônio das entidades que são compostas por pessoas.

A Contabilidade pode der conceituada, pelo menos, sob três ângulos: (1) sob o ponto de vista do acompanhamento das variações quantitativas e qualitativas do Patrimônio e, nesse caso, pode-se considerá-la como ciência, a definição preferida pelos neopatrimonialistas, quando se referem ao objeto da Contabilidade; (2) sob o ponto de vista do usuário da informação contábil, o fato de ser ciência ou não pouco importa; interessa a ele que a Contabilidade, ou melhor, o sistema de informação contábil lhe entregue, a um custo razoável, as informações e análises que permitirão uma ágil tomada de decisão. Existe, todavia, outra 
Perspectivas dos acadêmicos iniciantes e concluintes do curso de Ciências Contábeis em relação à profissão contábil UNEMAT - campus Tangará da Serra-MT

Lucivone Pereira Gomes, Margarida Alves Rocha, Carlos Rezende de Pádua Júnior, Fabiana Pereira Leite Lancelotti de Oliveira

visão da Contabilidade, qual seja a econômica, que observa a Contabilidade como (3) a disciplina que permite avaliar os recursos escassos colocados à disposição das entidades, bem como inferir sobre a eficiência e eficácia com que os mesmos foram manipulados (IUDÍCIBUS, 2004).

No entanto, a contabilidade possui métodos específicos para cada tipo de atividade empresarial, para que essas entidades possam realizar seus trabalhos e resolverem suas mais variadas situações de riscos, ameaças e oportunidades existentes de acordo com suas necessidades.

Quanto aos objetivos da Contabilidade, pode ser estabelecido como sendo o de fornecer informação estruturada de natureza econômica, financeira e, subsidiariamente, física, de produtividade e social, aos usuários internos e externos e à entidade objeto de Contabilidade.

Segundo os autores o objetivo da Contabilidade é o de fornecer informações estruturadas as quais ajudarão nas tomadas de decisões dentro das entidades para ajudar os empresários sobre as mais diversas situações a que ocorra dento de suas empresas. Conceituado por (IUDÍCIBUS; MARION, 2002).

A função fundamental da Contabilidade (...) tem permanecido inalterada desde seus primórdios. Sua finalidade é prover os usuários dos demonstrativos financeiros com informações que os ajudarão a tomar decisões. Sem dúvida, tem havido mudanças substanciais nos tipos de usuários e nas formas de informação que têm procurado. Todavia, esta função dos demonstrativos financeiros é fundamental e profunda. O objetivo básico dos demonstrativos financeiros é prover informações úteis para a tomada de decisões econômicas. Conforme cita, (IUDICIBUS, 2004).

Para Sá, (2002), "O nascimento da Contabilidade é o da inscrição de elementos da riqueza patrimonial, passando, aos poucos, o registro de melhor qualidade".

A evolução da Contabilidade se deu a partir do método das Partidas Dobradas, sendo que para todo Débito equivale o Crédito e vice-versa. Sobre este método existem várias especulações, mas ninguém sabe ao certo quem é o autor deste método que é o centro da contabilidade.

Admite-se que foram os sumério-babilônios os autores do sistema de "debito" e "crédito", baseado na identificação mental do que "é meu" e "é seu". As contas, como instrumentos de registros, já haviam nascido como primeiras manifestações inteligente do homem, mesmo antes que esse tivesse inventado a escrita ou soubesse calcular, não sendo de admirar que tivessem sido preocupação o desenvolvimento das aludidas formas de "guarda memória" de forma organizada (SÁ, 2004).

De acordo com Marion e Iudícibus (2002, P.32):

Concluindo que desde os povos mais primitivos, a Contabilidade já existia em função da necessidade de controlar, medir e preservar o patrimônio familiar e, até mesmo, em função de trocar bens para maior satisfação das pessoas.

A evolução da contabilidade vem sendo cada dia mais aperfeiçoado, pois surge a necessidade de mudanças para manter a preservação do patrimônio.

Sá (2002) afirma também que, "A evolução tem como conseqüência a quantidade de fatos a registrar, provocada pela evolução socioeconômica, somada à da qualidade dos escribas e matemáticos que se dedicavam aos registros contábeis". 
Perspectivas dos acadêmicos iniciantes e concluintes do curso de Ciências Contábeis em relação à profissão contábil UNEMAT - campus Tangará da Serra-MT

Lucivone Pereira Gomes, Margarida Alves Rocha, Carlos Rezende de Pádua Júnior, Fabiana Pereira Leite Lancelotti de Oliveira

O profissional é muito mais valorizado do que em décadas anteriores devido à evolução tanto econômicas como cultural do mundo e das pessoas, fazendo com que a profissão contábil seja bem mais aceita e possui um campo amplo de atuação dentro da sociedade. O mais interessante é que a contabilidade vai iniciar a sua fase adulta, fase racional, exatamente no aperfeiçoamento da imprensa por Gutemberg, na Alemanha, nos século XV D. C.

Afirma Iudícibus e Marion (2002): "Mais é interessante que a Contabilidade vai iniciar a sua fase adulta e fase racional, exatamente no aperfeiçoamento da Imprensa por Gutemberg, na Alemanha, nos século XV D. C”.

A contabilidade do Renascimento para a Ciência, o que a história tem mostrado é que a contabilidade torna-se importante à medida que há desenvolvimento econômico. Hoje por exemplo, a profissão é muito valorizada nos países do primeiro mundo. No Brasil, até a década de 60, este profissional era chamado de "guarda-livros", a nosso ver, título pejorativo e pouco indicador. Todavia, com o milagre econômico na década de 70 , essa expressão desapareceu e observou-se um excelente e valorizado mercado de trabalho para os contabilistas (IUDÍCIBUS; MARION 2002).

A contabilidade vem demonstrando uma excelente mudança com o decorrer do tempo em relação ao mercado de trabalho. Essa mudança decorre da evolução tanto econômica como social, trazendo para o mercado melhores condições tanto da parte financeiro como profissional, conforme citado pelo autor anteriormente.

Na seqüência foi abordado o tema, perspectiva da profissão contábil no Brasil.

\subsection{Profissão Contábil no Brasil}

De acordo com Revista Brasileira de Contabilidade RBC (maio/junho, p.53 2009) "A primeira regulamentação contábil no Brasil ocorreu por meio do Decreto Imperial n 4.475 do ano de 1870, no qual foi reconhecida oficialmente a Associação dos Guarda-Livros da Corte". Essa função foi se desenvolvendo com decorrer do tempo, até chegar ao ensino superior.

Já com relação à criação do curso de Ciências Contábeis deu-se por meio do DecretoLei $n^{\circ} 7.988$, de 22/9/1945, sendo que este criou o curso de Ciências Contábeis e Atuariais, conferindo este título aos bacharéis. Após isso, com o curso de Ciências Contábeis, ocorrida em 31/7/1951, com a Lei $n^{\circ} 1.401$, passou-se a conferir a titulação de Bacharel em Ciências Contábeis.

Ditado pela Revista Brasileira de Contabilidade, (maio/junho no 177 2009, p. 53).

Já a criação do curso de Ciências Contábeis deu-se por meio do Decreto-Lei ${ }^{\circ}$ 7.988, de 22/9/1945, sendo que este criou o curso de Ciências Contábeis e Atuariais, conferindo este título aos bacharéis. Após isso, com a criação efetiva do curso de Ciências Contábeis, que ocorreu em 31/7/1951, com a Lei no 1.401 , passou-se a conferir a titulação de Bacharel em Ciências Contábeis.

A Contabilidade possui um leque diversificado no que se refere à atuação do profissional contábil, podemos dizer que a tarefa básica do Contador é produzir e/ou gerenciar informações úteis aos usuários da Contabilidade para a tomada de decisões. Ressalta-se, entretanto, que, em nosso país, em alguns segmentos da nossa economia, principalmente na pequena empresa, a função do contador foi distorcida, estando voltada quase que exclusivamente para satisfazer às exigências do fisco (IUDÍCIBUS; MARION 2002). 
Perspectivas dos acadêmicos iniciantes e concluintes do curso de Ciências Contábeis em relação à profissão contábil UNEMAT - campus Tangará da Serra-MT

Lucivone Pereira Gomes, Margarida Alves Rocha, Carlos Rezende de Pádua Júnior, Fabiana Pereira Leite Lancelotti de Oliveira

Para Iudícibus e Marion (2002), "Outras áreas ainda ocupadas pelo Contador: Investigador de Fraude, Escritor, Parecerista, Avaliador de Empresas, Conselheiro Fiscal, Mediação e Arbitragem".

Segundo a idéia do autor a contabilidade como profissão possui campo muito amplo de atuação, pois proporciona uma variedade de oportunidades para a pessoa que optar por fazer o curso de contabilidade possuindo assim, várias alternativas para atuação profissional. Entre essas alternativas estão: Contabilidade Financeira, Contabilidade de Custos, Contabilidade Gerencial, Auditor Interno, Auditor Externo, Analista Financeiro, Perito Contábil, Consultor Contábil, Professor de Contabilidade, Cargos Públicos, Cargos Administrativos entre outros.

No Brasil a Legislação do profissional contábil Decreto-Lei no 9.295/46, afirma, “Cria o Conselho Federal de Contabilidade, define as atribuições do Contador e do Guarda-livros e dá outras providências".

De acordo com CFC (2003): "Declara atividade privativa dos Contabilistas a escrituração dos livros fiscais e revoga a Resolução no 36/48".

\subsection{Profissão no futuro}

Esta seção tem o objetivo de demonstrar as diversas áreas que o profissional tem para atuar, e como será o mercado de trabalho no futuro levando em consideração as mudanças que vem ocorrendo em todo o mundo.

A certificação do contador na Inglaterra é dada pela rainha. Nos Estados Unidos, se perguntar a alguém qual a vocação que seu filho deve seguir, aparecem às profissões de médico, advogado e contador. Em alguns estados americanos o contador é o mais bem remunerado entre as profissões liberais. Lá, os auditores são umas classes privilegiadas, ganham fortunas, jogam golfe e são muito respeitados. Isto acontece em outros países desenvolvidos, (MARION, 2010).

Dentro da Contabilidade Financeira, as especializações, como Contabilidade Rural, Contabilidade Hospitalar, Contabilidade Imobiliária etc. e os "casamentos" Contabilidade e Informática, Contabilidade e Direito Tributário etc., são excelentes opções para essa mudança de milênio, (MARION, 2010)

Muitas universidades querem introduzir mestrados e doutorados (com bons salários), mas não há ofertas de docentes e pesquisadores no mercado. Praticamente, não há autores, docentes de carreira e pesquisadores disponíveis. A demanda por docentes titulados e pesquisadores tem-se intensificado após a iniciativa do Provão, a ponto de existir instituição de ensino superior que propõe remuneração ao docente doutor de cinco aulas por cada aula dada, (MARION, 2010).

No momento atual brasileiro não vivemos esses privilégios. Na verdade, os benefícios estão chegando aos poucos dentro da profissão contábil. Segundo Marion no livro Contabilidade Empresarial, publicado pela Editora Atlas SA, inicia dizendo que, ao contrário de outras profissões, a Contabilidade oferece um leque de pelo menos dez alternativas diferentes de exercício profissional. Na verdade, na área de negócios a linguagem universal é a Contabilidade. Assim, como muitas pessoas querem aprender inglês como um idioma internacional para se comunicar, é mister se conhecer a Contabilidade para se comunicar no mundo dos negócios, (MARION, 2010). 
Perspectivas dos acadêmicos iniciantes e concluintes do curso de Ciências Contábeis em relação à profissão contábil UNEMAT - campus Tangará da Serra-MT

Lucivone Pereira Gomes, Margarida Alves Rocha, Carlos Rezende de Pádua Júnior, Fabiana Pereira Leite Lancelotti de Oliveira

Existe hoje um pouco mais de 100.000 contadores registrados em Conselhos Regionais em todo o país (os Estados Unidos formam 50.000 novos contadores a cada ano). Considerando que nosso universo de empresas chega a quase 4,5 milhões, podemos obter um quociente do profissional habilitado para cada 45 empresas. Em sentido meramente algébrico, cada contador que se forma teria 45 empresas aguardando seus serviços, (MARION, 2010)

De acordo com Marion (2010). "Para preparar essa demanda enorme de contadores são necessários docentes e pesquisadores. No Brasil temos hoje apenas 250 mestres em Contabilidade enquanto os Estados Unidos formam 6.000 a cada ano" (MARION, 2010).

Há somente 55 doutores (para mais de 330 cursos superiores de Contabilidade), enquanto os americanos formam 220 novos doutores por ano, não conseguindo, assim mesmo, atender a sua demanda. Os livros didáticos estão nas mãos de menos de meia dúzia de autores e atendem mais de $90 \%$ das instituições de ensino. Revistas e boletins são raríssimos pela escassez de autores.

Ressalta Marion (2010):

Temos somente 55 doutores (para mais de 330 cursos superiores de Contabilidade), enquanto os americanos formam 220 novos doutores por ano, não conseguindo, assim mesmo, atender a sua demanda. Os livros didáticos estão nas mãos de menos de meia dúzia de autores e atendem mais de $90 \%$ das instituições de ensino. Revistas e boletins são raríssimos pela escassez de autores.

Já em relação ao ponto de vista financeiro, em termos de mercado de trabalho para o contador, as perspectivas são excelentes. Na verdade, ainda estamos no limiar de uma era em que será reconhecida toda a importância da função contábil dentro das entidades. O número de bons profissionais, com ampla visão de administração financeira é tão escasso no momento que os poucos que a possuem e, portanto, têm condições de assumir posições de controladores, diretores financeiros, chefes de Departamento de Contabilidade e de Custos, auditores internos e externos, têm obtido remuneração e satisfação profissional. Conforme cita, (IUDÍCIBUS 2004).

No que tange à nova tendência do fim do emprego duradouro, o profissional contábil é levado a administrar sua própria carreira. Requer o fato de estar atento para as oportunidades de mercado, descobrir os nichos existentes e investir em marketing pessoal (muito mal cuidado, diga-se de passagem, pelos profissionais contábeis), (MARION, 2010).

Para melhorar o marketing pessoal dever-se-ia pensar em ser executivo-chefe de si mesmo. As pessoas físicas são empresas que precisam ter uma marca que as identifique. Os profissionais necessitam de marketing pessoal para fazer negócios. Agentes livres em que a profissão e a economia proporcionam chances de destaque e possibilidade e de marca registrada, (MARION, 2010).

Portanto, para se destacar no mercado de trabalho tem-se que fazer com que o marketing pessoal seja diferenciado dos demais, para obter êxito na profissão. Por fim, conclui que as perspectivas da profissão realmente são extraordinárias, mas nada vai acontecer sem um planejamento adequado. Nos dias que seguem, as empresas serão vistas como clientes (ou, quem sabe, parceiras); os profissionais como fornecedores de serviços, exigindo-se por parte destas diversas ênfases: competência, profissionalismo, inteligência emocional e marketing pessoal (ver o mundo como um mercado e as pessoas em volta como clientes), (MARION, 2010). 
Perspectivas dos acadêmicos iniciantes e concluintes do curso de Ciências Contábeis em relação à profissão contábil UNEMAT - campus Tangará da Serra-MT

Lucivone Pereira Gomes, Margarida Alves Rocha, Carlos Rezende de Pádua Júnior, Fabiana Pereira Leite Lancelotti de Oliveira

\section{METODOLOGIA}

A metodologia utilizada foi de coleta de dados baseados em questionários contendo treze perguntas objetivas sendo aplicados entre os acadêmicos iniciantes (2010/2) e concluintes (2007/1). Dos acadêmicos iniciantes matriculados na Instituição foram apenas trinta e cinco pesquisados. Já os concluintes (2007/1), foram pesquisados somente os que estão regularmente matriculados em todas as disciplinas do oitavo semestre, totalizando 14 acadêmicos, do curso de Ciências Contábeis, UNEMAT, campus de Tangará da Serra - MT.

A pesquisa teve como principal metodologia aplicação de questionário no primeiro semestre (2010/2) e no oitavo semestre (2007/1), para obtenção dos resultados. Esse questionário continha 13 perguntas objetivas, realizado por amostragem e por população com alternativas, para que o aluno escolhesse uma única resposta entre as alternativas sugeridas.

Os resultados foram demonstrados através de tabelas comparativas para os iniciantes/concluintes, sendo composta de cálculos estatísticos. Segue a discussão dos resultados. O levantamento de dados foi por amostragem para os iniciantes, e por população entre os concluintes e ocorreu no mês de setembro de 2010, realizado em sala de aula sendo feito somente em uma etapa. Os resultados obtidos foram demonstrados mediante aplicação de cálculos estatísticos, com elaboração de tabelas comparativas definidos por sexo, faixa etária, iniciantes e concluintes, onde foram demonstradas as expectativas e os motivos que influenciaram os acadêmicos na escolha do curso que estão buscando como profissão futura.

Teve ainda como metodologia a pesquisa bibliográfica, descritiva, explicativa e quantitativa, pois os resultados obtidos foram também demonstrados por dados estatísticos com percentuais nas respostas dos pesquisados. Sendo os estudos realizados e conceituados com autores renomados que contribuíram para o desenvolvimento da pesquisa. Desta forma, o material desenvolvido foi contextual e de fácil entendimento através da leitura de artigos, revistas, livros e internet, que contribuiu para o desenvolvimento do trabalho, assim obtendo os resultados desejados.

\section{DISCUSSÃO DE RESULTADOS.}

Esta seção tem o objetivo de apresentar os resultados da pesquisa de campo. Incialmente foram apresentadas as características dos entrevistados. Em seguida as respostas às questões principais da pesquisa.

\subsection{Perfil dos pesquisados}

Buscou-se demonstrar o perfil dos pesquisados, obtendo os seguintes resultados. Como se observa, o número de alunos do sexo feminino que ingressam na universidade é maior em relação do sexo masculino, apresentando percentual acima dos $50 \%$, dos pesquisados. Os acadêmicos concluintes que serão graduados, também equivalem ao sexo feminino, apresentando maior percentual. Nota-se que os homens estão cada vez mais longe 
Perspectivas dos acadêmicos iniciantes e concluintes do curso de Ciências Contábeis em relação à profissão contábil UNEMAT - campus Tangará da Serra-MT

Lucivone Pereira Gomes, Margarida Alves Rocha, Carlos Rezende de Pádua Júnior, Fabiana Pereira Leite Lancelotti de Oliveira

das escolas e faculdades, esses resultados são preocupantes, pois, está sendo predominante o sexo feminino em várias áreas profissionais. (Tabela 1).

Tabela 1. Distribuição dos entrevistados com relação ao gênero.

\begin{tabular}{l|c|c}
\hline Resposta & Iniciantes \% & Concluintes \% \\
\hline Masculino & $40,00 \%$ & $35,72 \%$ \\
\hline Feminino & $60,00 \%$ & $64,28 \%$ \\
\hline
\end{tabular}

\subsection{Faixa etária dos pesquisados}

Verifica-se que a idade que predomina entre os acadêmicos iniciantes fica na faixa etária de 18 a 22 anos, significa que cada vez mais pessoas jovens estão buscando curso de nível superior devido ao mercado competitivo, e também devido às mudanças em todo cenário mundial e consequentemente profissional as pessoas estão preocupadas em se especializar em cursos de nível superior. Entre os acadêmicos concluintes a idade variou de 24 a 26 e também acima dos 26 anos, bem diferente dos resultados dos iniciantes. (Tabela 2).

Tabela 2. Distribuição dos entrevistados com relação a idade.

\begin{tabular}{l|c|c}
\hline Resposta & Iniciantes \% & Concluintes \% \\
\hline Menos de 18 anos & $8,57 \%$ & 0 \\
\hline 18 a 22 anos & $57,14 \%$ & $28,57 \%$ \\
\hline 22 a 24 anos & $17,14 \%$ & 0 \\
\hline 24 a 26 anos & $5,71 \%$ & $35,72 \%$ \\
\hline Acima de 26 anos & $11,43 \%$ & $35,71 \%$ \\
\hline
\end{tabular}

\subsection{Na escolha do curso}

Os fatores e motivos que contribuíram na escolha do curso entre os pesquisados iniciantes e concluintes foram: pelos iniciantes foi referente à boa perspectiva do curso com $37,14 \%$, e em segundo ficou o fator mercado de trabalho com $25,71 \%$. O mesmo foi para a concluinte em relação ao fator boa perspectiva do curso com 42,85\%, e em segundo ficou a falta de opção com $28,57 \%$ dos pesquisados. Nota-se uma semelhança entre os pesquisados, relacionado à boa visão e boas perspectivas do curso. $\mathrm{O}$ curso de ciências contábeis está muito mais valorizado do que em épocas anteriores, o mercado de trabalho está valorizando mais esse profissional. (Tabela 3 ).

Tabela 3. Distribuição dos entrevistados com relação a escolha do curso de Ciências Contábeis.

\begin{tabular}{l|c|c}
\hline Resposta & Iniciantes \% & Concluintes \% \\
\hline Família & $2,86 \%$ & $0,00 \%$ \\
\hline Falta de opção & $5,71 \%$ & $28,57 \%$ \\
\hline
\end{tabular}


Perspectivas dos acadêmicos iniciantes e concluintes do curso de Ciências Contábeis em relação à profissão contábil UNEMAT - campus Tangará da Serra-MT

Lucivone Pereira Gomes, Margarida Alves Rocha, Carlos Rezende de Pádua Júnior, Fabiana Pereira Leite Lancelotti de Oliveira

\begin{tabular}{l|c|c}
\hline Mercado de Trabalho & $25,71 \%$ & $7,15 \%$ \\
\hline Horário do curso & $5,71 \%$ & $0,00 \%$ \\
\hline Boa perspectiva do curso & $37,14 \%$ & $42,85 \%$ \\
\hline Concursos & $20,00 \%$ & $0,00 \%$ \\
\hline Instituição Publica & $2,85 \%$ & $21,43 \%$ \\
\hline
\end{tabular}

Outros?

\subsection{Expectativas dos acadêmicos}

Identificou-se que a expectativa entre os acadêmicos com relação ao curso tanto os iniciantes e concluintes foram semelhantes escolhendo como primeira opção expectativa voltada para concursos públicos, com $62,85 \%$ e $42,85 \%$. A segunda opção foi de abrir próprio negócio com $25,72 \%$ e $35,72 \%$. Os pesquisados consideram que o curso proporciona maior possibilidade de estar trabalhando na área pública, pois, existem muitos concursos para o profissional contábil, e a remuneração é excelente, sem contar na estabilidade que proporciona a esses servidores públicos. (Tabela 4).

Tabela 4. Distribuição dos entrevistados com relação as expectativas dos acadêmicos ao iniciar o curso de Ciências Contábeis.

\begin{tabular}{l|c|c}
\hline Resposta & Iniciantes \% & Concluintes \% \\
\hline Expectativa de concursos & $62,85 \%$ & $50,00 \%$ \\
\hline $\begin{array}{l}\text { Expectativa de trabalhar em empresas de } \\
\text { terceiros }\end{array}$ & $5,71 \%$ & $7,15 \%$ \\
\hline Expectativa de abrir proprio negócio & $25,72 \%$ & $28,57 \%$ \\
\hline Expectativa voltada ao ensino & $5,72 \%$ & $14,28 \%$ \\
\hline Outros?
\end{tabular}

\subsection{Os acadêmicos gostam de contabilidade}

Os pesquisados responderam que gostam muito de contabilidade, ficando com um percentual para os iniciantes acima dos $50 \%$ e os concluintes atingiu os $50 \%$, esse índice não é considerado muito alto, pois os acadêmicos buscam mesmo com o curso de ciências contábeis a expectativa para ingressar na área pública, porque o curso possui esse diferencial em relação a outras profissões, portanto o fator gostar do curso não é considerado muito relevante. Mesmo a pesquisa demonstrando percentuais baixos, os pesquisados ainda assim gostam do curso, esses resultados mostram que a opção irá contribuir e muito na formação profissional, afinal eles estão buscando como profissão futura. O profissional trabalha com prazer e encara os problemas da sua profissão com maior flexibilidade quando gosta de exercer sua atividade. (Tabela 5).

Tabela 5. Distribuição dos entrevistados com relação a opinião sobre o curso.

\begin{tabular}{l|r|r}
\hline Resposta & Iniciantes \% & Concluintes \% \\
\hline Gosta um pouco & $37,14 \%$ & $35,71 \%$ \\
\hline \multicolumn{3}{|c}{} \\
\hline Volume 2, Número 3 \\
Jan./Jun. 2013
\end{tabular}


Perspectivas dos acadêmicos iniciantes e concluintes do curso de Ciências Contábeis em relação à profissão contábil UNEMAT - campus Tangará da Serra-MT

Lucivone Pereira Gomes, Margarida Alves Rocha, Carlos Rezende de Pádua Júnior, Fabiana Pereira Leite Lancelotti de Oliveira

\begin{tabular}{l|c|c}
\hline Gosta muito & $60,00 \%$ & $57,14 \%$ \\
\hline Não gosta & $2,86 \%$ & $7,15 \%$ \\
\hline
\end{tabular}

\subsection{Como os acadêmicos identificam o curso de Ciências Contábeis}

Os resultados obtidos na tabela 6 refletem que os acadêmicos iniciantes como os concluintes identificam o curso como sendo um preparo para concursos públicos, consideram que o profissional contábil tem certa facilidade de estar ingressando na carreira pública, atingindo percentual de $51,42 \%$, para os iniciantes e $42,86 \%$ para os concluintes. A opção de menor relevância foi para obter nível superior com 2,86\%. E a segunda opção para ambos foi mercado de trabalho, acreditam que há um mercado grande para essa profissão, com uma variedade de áreas para estar trabalhando, por isso acredita ser proveitoso fazer o curso de ciências contábeis. (Tabela 6).

Tabela 6. Distribuição dos entrevistados com relação a preparação do curso para o mercado.

\begin{tabular}{l|c|c}
\hline Respostas & Iniciantes \% & Concluintes \% \\
\hline Apenas para obter nível superior & $2,86 \%$ & $14,28 \%$ \\
\hline Mercado de trabalho & $25,71 \%$ & $14,28 \%$ \\
\hline Concursos públicos & $51,42 \%$ & $42,86 \%$ \\
\hline Desejo de autonomia & $8,58 \%$ & $14,28 \%$ \\
\hline Maior remuneração & $11,43 \%$ & $14,29 \%$ \\
\hline
\end{tabular}

\subsection{Tempo que atua na área.}

Buscando identificar a atuação dos pesquisados, quase $100 \%$ dos iniciantes não trabalham na área, apenas uma pessoa já está trabalhando, já os concluintes mais de $50 \%$ já atuam na área. Isso demonstra que ao iniciar o curso a maioria não consegue ingressar facilmente na área, mas após certo tempo de curso o percentual muda. Nessa pesquisa mostrou que os concluintes ultrapassam 50\%, dos que já conseguiram emprego antes de tornar graduado. (Tabela 7).

Tabela 7. Distribuição dos entrevistados com relação ao tempo de atuação na área contábil.

\begin{tabular}{l|c|c}
\hline Respostas & Iniciantes \% & $\begin{array}{c}\text { Concluintes } \\
\%\end{array}$ \\
\hline
\end{tabular}


Perspectivas dos acadêmicos iniciantes e concluintes do curso de Ciências Contábeis em relação à profissão contábil UNEMAT - campus Tangará da Serra-MT

Lucivone Pereira Gomes, Margarida Alves Rocha, Carlos Rezende de Pádua Júnior, Fabiana Pereira Leite Lancelotti de Oliveira

\begin{tabular}{l|c|c}
\hline Não atua & $97,14 \%$ & $57,14 \%$ \\
\hline Até 2 anos & $2,86 \%$ & $21,43 \%$ \\
\hline 3 a 5 anos & 0 & $21,43 \%$ \\
\hline 6 a 10 anos & 0 & 0 \\
\hline Acima de 10 anos & 0 & 0 \\
\hline
\end{tabular}

\subsection{Contabilidade não se aprende na faculdade, mas sim, na prática}

$\mathrm{Na}$ pesquisa identificou que entre os alunos iniciantes $51,42 \%$ discordam, e os que concordam ficou com $25,72 \%$, resultado muito relevante, pois a maioria deles acredita que as disciplinas aplicadas ao longo do curso contribuem para o aprendizado e formação profissional. No entanto para os concluintes concordam com a pergunta passando dos $50 \%$ e concordam plenamente $7,15 \%$ dos pesquisados. Os resultados dos concluintes demonstram certa insatisfação perante o ensino aplicado nessa Instituição. É significativo o nível de concordância entre os alunos concluintes, talvez com algumas mudanças no método de ensino contribuiria para que o quadro de insatisfação mudasse, trazendo melhoras tanto para o curso quanto para a Instituição. (Tabela 8).

Tabela 8. Distribuição dos entrevistados com relação a questão: no seu conhecimento, a contabilidade não se aprende na faculdade, mas sim, na prática?

\begin{tabular}{l|c|c}
\hline & Iniciantes \% & Concluintes \% \\
\hline Discordo plenamente & $17,14 \%$ & 0 \\
\hline Discordo & $51,42 \%$ & $35,71 \%$ \\
\hline Concordo & $25,72 \%$ & $57,14 \%$ \\
\hline Concordo plenamente & $5,72 \%$ & $7,15 \%$ \\
\hline
\end{tabular}

\section{9 Áreas que deseja se especializar}

Entre as especializações sugeridas no questionário, os acadêmicos iniciantes desejam se especializar no cargo administrativo-contador geral, com percentual de $28,58 \%$, ficando em segundo a opção de auditor - interno/externo com $25,71 \%$, uma área que está em alta nos dias atuais, e em terceiro a opção de ser professor com 11,42\%. A maioria dos concluintes ainda não sabe que áreas irão se especializar com percentual considerado alto com $42,86 \%$, isso é fator preocupante, pois já estão concluindo a graduação e ainda não sabem que área se especializar no momento que concluir seu curso superior. Apenas alguns responderam que irá se especializar em umas dessas áreas apontadas na pesquisa. Ainda entre os acadêmicos concluintes ninguém tem interesse no momento de atuar como profissional liberal, esses resultados contraria a tabela 6 , pois responderam que tem desejo de atuar como profissional liberal com 14,28\%. (Tabela 9).

Tabela 9. Distribuição dos entrevistados com relação a área da contabilidade que desejam se especializar. 
Perspectivas dos acadêmicos iniciantes e concluintes do curso de Ciências Contábeis em relação à profissão contábil UNEMAT - campus Tangará da Serra-MT

Lucivone Pereira Gomes, Margarida Alves Rocha, Carlos Rezende de Pádua Júnior, Fabiana Pereira Leite Lancelotti de Oliveira

\begin{tabular}{l|c|c}
\hline \hline Resposta & Iniciantes \% & Concluintes \% \\
\hline Auditor - interno/externo & $25,71 \%$ & $14,28 \%$ \\
\hline Professor & $11,42 \%$ & $14,28 \%$ \\
\hline Agente fiscal & $2,86 \%$ & $0,00 \%$ \\
\hline Perito & $5,71 \%$ & $14,29 \%$ \\
\hline Não sei & $14,28 \%$ & $42,86 \%$ \\
\hline Contador gerencial-custo & $5,71 \%$ & $0,00 \%$ \\
\hline $\begin{array}{l}\text { Cargo administrativo - contador } \\
\text { geral }\end{array}$ & $28,58 \%$ & $14,29 \%$ \\
\hline Autônomo & $5,72 \%$ & $0,00 \%$ \\
\hline Outros. Qual? & & \\
\hline
\end{tabular}

\subsection{Perspectivas em relação à profissão contábil}

Sobre a perspectiva dos pesquisados os resultados apontados entre os iniciantes e concluintes, teve como maior percentual de respostas à opção facilidade de ingressar na área, ambos possuem essa mesma perspectiva para o profissional contábil, após a graduação. Entre os iniciantes ainda foi maior que entre os concluintes com $88,57 \%$ para $64,28 \%$. Não houve nenhuma resposta relacionada à opção status na sociedade, mas a pesquisa obteve também resposta a opção apenas agregar conhecimento com 11,43\% para iniciantes e 35,72\% para concluintes, demonstrando que para alguns alunos é importante apenas sua graduação. (Tabela 10).

Tabela 10. Distribuição dos entrevistados com relação a perspectiva da profissão contábil após graduação.

\begin{tabular}{l|c|c}
\hline Resposta & Iniciantes \% & Concluintes \% \\
\hline Facilidade de ingressar na área & $88,57 \%$ & $64,28 \%$ \\
\hline Status na sociedade & 0 & $0,00 \%$ \\
\hline Apenas agregar conhecimento & $11,43 \%$ & $35,72 \%$ \\
\hline
\end{tabular}

\subsection{Como se mantém informado sobre a profissão contábil}

Nessa tabela a pesquisa é direcionada ao método que os alunos se mantêm informados com relação à profissão. Os iniciantes responderam que é através da internet que se mantém informado com $60,00 \%$ dos pesquisados. Os concluintes também apresentam percentual de $50 \%$, que é através desse mecanismo que se mantém informado. Os acadêmicos em sua maioria estão deixando de lados os livros e revistas que é de relevância para esse profissional. A internet ajuda muito no nosso mundo globalizado, mas não deve esquecer que há outros meios para manter-se atualizado, não focar somente no mundo virtual. Os concluintes também responderam que mantém contato com profissionais da área, sendo esse meio muito importante, porque acaba ajudando ambos nas dúvidas que possam ocorrer no dia a dia desses profissionais. Teve também como resposta de um acadêmico, que pesquisa 
Perspectivas dos acadêmicos iniciantes e concluintes do curso de Ciências Contábeis em relação à profissão contábil UNEMAT - campus Tangará da Serra-MT

Lucivone Pereira Gomes, Margarida Alves Rocha, Carlos Rezende de Pádua Júnior, Fabiana Pereira Leite Lancelotti de Oliveira

informações através do informativo IOB (Informações Objetivas de Contabilidade e Fiscalidade Ltda). (Tabela 11).

Tabela 11. Distribuição dos entrevistados com relação a forma de aquisição da informação contábil.

\begin{tabular}{l|c|c}
\hline Resposta & Iniciantes \% & Concluintes \% \\
\hline Internet & $60,00 \%$ & $50,00 \%$ \\
\hline Revistas & 0 & $0,00 \%$ \\
\hline Livros & $8,57 \%$ & $14,28 \%$ \\
\hline Jornais & $5,71 \%$ & $7,15 \%$ \\
\hline $\begin{array}{l}\text { Contato com colegas } \\
\text { profissionais da área }\end{array}$ & $25,72 \%$ & $21,42 \%$
\end{tabular}

Outros. Quais? Informativo IOB

\subsection{Em que nível a Instituição atende suas expectativas do curso}

Diante dos resultados da tabela 5 os pesquisados mesmo gostando pouco do curso eles se contradizem um pouco nas respostas na tabela 12. Pois, verifica-se que com os resultados obtidos nessa tabela, para os iniciantes a Instituição atende suas expectativas, considerada por eles o curso sendo como muito bom, com $54,28 \%$ dos pesquisados. Por outro lado, os concluintes consideram o curso somente bom com $78,57 \%$ dos pesquisados. A tabela mostra que perante os pesquisados o curso é de boa qualidade praticada nessa Instituição. Nenhum dos alunos respondeu que o curso é considerado ruim, mas alguns concluintes disseram que o curso é considerado péssimo. Nota-se uma insatisfação entre alguns alunos que estudam nessa Instituição. (Tabela 12).

Tabela 12. Distribuição dos entrevistados com relação ao nível no qual a Instituição atende suas expectativas do curso de contabilidade.

\begin{tabular}{l|c|c}
\hline & Iniciantes \% & Concluintes \% \\
\hline Excelente & $25,72 \%$ & $0,00 \%$ \\
\hline Muito bom & $54,28 \%$ & $14,28 \%$ \\
\hline Bom & $20,00 \%$ & $78,57 \%$ \\
\hline Ruim & 0 & 0 \\
\hline Péssimo & 0 & $7,15 \%$ \\
\hline
\end{tabular}

\subsection{Aproveitamentos nas disciplinas acadêmicas é importante para a formação do currículo do profissional contábil}

Por fim, também procurou identificar entre os acadêmicos pesquisados se consideram que um bom aproveitamento das disciplinas estudadas é relevante para a formação do currículo profissional. Os iniciantes e concluintes responderam que concordam ou concordam plenamente, nenhum dos alunos discordaram dessa questão, alguns ficaram na 
Perspectivas dos acadêmicos iniciantes e concluintes do curso de Ciências Contábeis em relação à profissão contábil UNEMAT - campus Tangará da Serra-MT

Lucivone Pereira Gomes, Margarida Alves Rocha, Carlos Rezende de Pádua Júnior, Fabiana Pereira Leite Lancelotti de Oliveira

opção de neutro, variando de $2,85 \%$ para iniciantes e $14,28 \%$ para os concluintes. Esses resultados mostram que as disciplinas estudadas é a base para o conhecimento teórico, e a prática é o complemento da formação profissional. Para que haja execução do trabalho com qualidade, é necessário unir esses conhecimentos, que com certeza irá ajudar para formação dos futuros contadores. (Tabela 13).

Tabela 13. Distribuição dos entrevistados com relação a questão: o perfeito aproveitamento nas disciplinas acadêmicas é de fundamental importância para a formação do currículo do profissional contábil?

\begin{tabular}{lc|c}
\hline & Iniciantes \% & Concluintes \% \\
\hline Concordo totalmente & $48,57 \%$ & $28,57 \%$ \\
\hline Concordo & $48,57 \%$ & $57,14 \%$ \\
\hline Discordo & $0 \%$ & $0,00 \%$ \\
\hline Neutro & $2,85 \%$ & $14,28 \%$ \\
\hline
\end{tabular}

\section{CONSIDERAÇÕES FINAIS}

Os futuros profissionais contadores, devem utilizar todos os meios de informações que existem para manter-se atualizado, pois, mudanças ocorrem constantemente em todos os meios profissionais, sendo necessário estar inteiradas das informações. Cada profissional para ser reconhecido pelo trabalho depende do próprio esforço, deve ter o diferencial de forma a destacar a prestação de serviço dos demais, não fazendo somente o necessário, mas sim, ajudando o cliente nas tomadas de decisões em geral.

A pesquisa teve como problema: Quais são as expectativas dos acadêmicos do curso de Ciências Contábeis iniciantes 2010/2 e concluintes 2007/1 em relação à profissão contábil?

As hipóteses consideradas foram às seguintes:

H1-A escolha do curso de ciências contábeis pelos acadêmicos iniciantes e concluintes (2010/2 - 2007/1) reflete o desejo de serem profissionais liberais. Nos resultados obtidos, essa hipótese foi validada parcialmente. Apenas dois alunos iniciantes responderam que tem desejo de serem profissionais liberais, representando 5,72\%. Diferentemente dos concluintes não obteve nenhuma resposta da pergunta acima comentada, não possuem interesse de serem profissionais liberais, a visão do curso é direcionado mais para carreiras administrativas, professor e auditor, entre outros. Mas ainda o maior percentual de respostas foi que não sabem que áreas irão se especializar, apresentando percentual preocupante, com 42,86\% dos pesquisados, já que estão na reta final do curso.

Os pesquisados mesmo respondendo em outras questões que tem interesse na área pública, nessa questão quase não responderam que tem o desejo de trabalhar com agente fiscal e perito que são carreiras da área pública.

H2 - Os acadêmicos têm como expectativa dessa profissão ingressar na área pública, (concursos públicos). A hipótese foi validada, os alunos pesquisados acreditam que o curso de ciências contábeis proporciona mais facilidade de atuar na área pública pela quantidade de concursos que existem para o profissional. $O$ estudo dessa pesquisa procurou identificar os motivos e influências que levaram os acadêmicos a ingressarem na área profissional. 
Perspectivas dos acadêmicos iniciantes e concluintes do curso de Ciências Contábeis em relação à profissão contábil UNEMAT - campus Tangará da Serra-MT

Lucivone Pereira Gomes, Margarida Alves Rocha, Carlos Rezende de Pádua Júnior, Fabiana Pereira Leite Lancelotti de Oliveira

Mediante os resultados o problema e os objetivos foram atingidos, tornando o estudo relevante, apresentando que os motivos que levaram os alunos a optarem pelo curso foram à boa perspectiva e carreiras públicas. E principalmente gostam do curso que escolheram como profissão do futuro. Também possuem boa visão do profissional sobre o mercado de trabalho, e consideram que há certa facilidade de estar atuando na área.

As expectativas relacionadas à Instituição foram consideradas pela maioria como de boa qualidade, isso demonstra que o curso é bem aceito, haja vista, é fator relevante para o conhecimento daqueles que trabalham e contribuem para o crescimento e continuidade dessa Instituição de Ensino. O estudo contribuiu também para ter conhecimentos sobre o que os futuros contadores esperam do curso que será sua profissão.

O objetivo principal foi demonstrar o que os alunos realmente pensam e sabem sobre a profissão contábil. Se eles buscaram somente a obtenção do diploma de nível superior, ou pretendem continuar após a conclusão do curso se especializando. O estudo contribui também para a Instituição, conhecendo as opiniões dos alunos que buscaram a UNEMAT para sua formação acadêmica.

Um dado relevante que observa na pesquisa, demonstra que o bom aproveitamento das disciplinas aplicadas no decorrer do curso contribui na formação do currículo acadêmico. Os pesquisados também identificam o curso como sendo um preparo para concursos públicos

Uma sugestão para os futuros contadores é que não fiquem somente buscando informações no mundo virtual, mas sim, pesquisas em livros, revistas e jornais. E não façam somente o necessário para seus clientes, mas que trabalhem de forma integrada ajudando tanto na área fiscal quanto gerencial, que na maioria entre os profissionais não acontece. Precisamos de profissionais que demonstrem mais atitude e vontade de realizar trabalhos precisos e soluções rápidas, pois, a concorrência está cada vez mais acirrada em todas as categorias profissionais, e os que se destacam no mercado são aqueles que realmente possuem o diferencial em sua bagagem.

\section{REFERÊNCIAS BIBLIOGRAFICAS}

CONSELHO FEDERAL CONTABILIDADE, Legislação da profissão contábil. - Brasília: CFC, 2003.

CAVAlCANTE, C.H. L. Revista Brasileira de Contabilidade: Percepção dos alunos iniciantes e concluintes do Curso de Ciências Contábeis sobre a profissão contábil. Conselho Federal de Contabilidade, 2009. 51p.

IUDÍCIBUS, Sérgio de, MARION, José Carlos. Introdução à teoria da contabilidade para o nível de graduação. - 3. ed. - São Paulo: Atlas, 2002.

IUDÍCIBUS, Sérgio de. Teoria da contabilidade. - 7. ed. - São Paulo: Atlas, 2004.

MARION, José Carlos. Contabilidade Básica. - 7. ed.- São Paulo: Atlas, 2004. 
Perspectivas dos acadêmicos iniciantes e concluintes do curso de Ciências Contábeis em relação à profissão contábil UNEMAT - campus Tangará da Serra-MT

Lucivone Pereira Gomes, Margarida Alves Rocha, Carlos Rezende de Pádua Júnior, Fabiana Pereira Leite Lancelotti de Oliveira

MARION, José Carlos. Preparando-se para a profissão do futuro - Disponível em: $<$ http://www.marion.pro.br>. Acesso em: 16 de jun. de 2010.

RIBEIRO, Osni Moura. Contabilidade Básica. - 2. ed.- São Paulo Saraiva, 2009.

SÁ, Antônio Lopes de. Teoria da contabilidade. - 3. ed. - São Paulo: Atlas: 2002. 